\title{
GAMIFICATION E A WEB 2.0: planejando processo ensino-aprendizagem
}

\author{
W. S. MONTE ${ }^{*}$, M. M. BARRETO e A. B. ROCHA
}

Faculdade Vale do Jaguaribe, Departamento de Gestão. washington.monte@fvj.br ${ }^{*}$

submetido 10/03/2017 - Aceito 24/07/2017

DOI: 10.15628/holos.2017.5759

\section{RESUMO}

Este trabalho tem a finalidade de apresentar estratégias de utilização de plataforma digital para engajar e dinamizar o processo de ensino. Compreendo assim o conceito da gamificação como um processo que pode ser desenvolvido no ensino-aprendizagem, alinhando os conceitos Web 2.0. Desde o seu aparecimento a Internet (Web), a gamificação tem se apresentado como uma poderosa ferramenta que pode ser utilizada em vários contextos, inclusive na educação, com suas interfaces interativas e dinâmicas. A gamificação do inglês gamification um é conceito que reflete: engajamento, jogabilidade, sistemas de recompensas e ensinos colaborativos. A proposta é apresentar uma metodologia baseada em 3 etapas: A Etapa 01 corresponde à parte de planejamento onde professor pode organizar, a partir de vários pontos: textos, situação problema, a temática de uma aula. A Etapa 02 momento da interação do professor com a plataforma Socrative, criação dos questionários. Etapa 03, momento da aula, onde o professor disponibiliza o acesso por meio de código, de forma que os alunos tenham a possibilidade de acessar os quiz e estudar de modo colaborativo (equipes de estudos) e individual, assim, tendo condições para rever o conteúdo, estudar em casa ou no laboratório de informática da instituição de ensino ou de outro local que lhe for conveniente, por sua característica multi-plataforma: celular, tablet. O planejamento gamificado torna a aula mais inovadora e interativa, onde os alunos, passam a ser agentes ativos do processo de ensino-aprendizagem.

PALAVRAS-CHAVE: Educação, Tecnologia, Ensino.

\section{GAMIFICATION AND THE WEB 2.0: planning teaching-learning process}

\begin{abstract}
This work has the purpose of presenting strategies of use of digital platform to engage and dynamize the teaching process. I thus understand the concept of gamification a process that can be developed in teaching-learning, aligning the concepts Web 2.0. Since its inception the Internet (Web) has been presented as a powerful tool that can be used in several contexts, including education, with its interactive and dynamic interfaces. The gamification of English gamification is concept that reflects: engagement, gameplay, reward systems and collaborative teachings. The proposal is to present a methodology based on 3 steps: Step 01 corresponds to the planning part where teacher can
\end{abstract}

from several points: texts, problem situation, thematic of a lesson. Step 02, moment of teacher interaction with Socrative platform, creation of questionnaires, Step 03, moment of class, where the teacher provides access through code, so that students have the possibility to access the quizzes and study (Study teams) and individual, thus being able to review the content, study at home or in the computer laboratory of the educational institution or another location that is convenient, for its multi-platform feature: cell phone, tablet. Skimmed planning makes the classroom more innovative and interactive, where students become active agents of the teaching-learning process.

KEYWORDS: Education, Technology, Teaching. 


\section{APRESENTAÇÃO}

Esse trabalho pretende apresentar estratégias de utilização de plataforma digital para engajar e dinamizar o processo de ensino. Compreendo assim o conceito da gamificação como um processo que pode ser desenvolvido no ensino-aprendizagem, alinhando os conceitos Web 2.0. Quando a internet começou a dar seus primeiros passos, ninguém imaginava sua rápida popularização. Seu surgimento ocorreu para facilitar a troca de informações, e assim, nasceu a internet 1.0, sem interatividade, estática e sem aparência agradável. No entanto, essa tecnologia passou a ser utilizada para troca de informações entre instituições de ensino e, logo depois, para fins comerciais, ganhando assim velocidade, interatividade, formas e cores, ocorrendo o fenômeno conhecido como "Bolha da Web" - expressão utilizada por volta do ano 2000. Porém, quando a internet passou a ter a participação das massas, ou seja, quando os internautas (usuários) começaram a opinar e modificar o próprio conteúdo do meio virtual, surgiu a internet 2.0 ou Web 2.0.

A Web 2.0 passou a possibilitar que usuários e empresas, com pouco ou nenhum conhecimento tivessem acesso a uma gama de serviços agora disponíveis ao alcance de um click. A Web torna-se mais interativa no século XX, onde as informações cruzam o planeta em tempo real e as comunicações se integram. Esta interatividade vem sendo cada vez mais aprimorada pelas tecnologias interativas. Entender esse mundo virtual para alguns autores é entender o próprio ser humano e as suas ansiedades em um mundo pós-moderno (ADOLPHO, 2009).

O desenvolvimento das Tecnologias da Informação e Comunicação - TIC's, trousse uma nova perspectiva para os produtos e serviços disponíveis pelos veículos de comunicação, na verdade, o surgimento de novos meios comunicação já tem em sua constituição a interação entre quem produz o conteúdo e seu público (AMORA, 2008).

Com um fluxo maior de informações circulando pela Web 2.0, novos conceitos passam a surgir, um desses conceitos que vêm apresentando uma nova abordagem para vários contextos é o "Gamificação" (neologismo) ou do inglês Gamification, é uma nomenclatura que vem sendo utilizada explicar propostas que são empregadas como: engajamento, jogabilidade, sistemas de recompensas e ensinos colaborativos (na área da educação). Esse termo apareceu em uma conferência do Technology, Entertainment, Design - TED, em 2002 nos Estados Unidos e foi apresentado pela Jane McGonigal, mas somente depois de 2010 é que o termo ganhou o mundo. Assim, as propostas de utilização do conceito estão sendo utilizadas por várias comunidades científicas, chegando à educação como proposta de aprimoramento das práticas e dos processos de aprendizagens. No decorrer do texto, utilizaremos a expressão gamificação.

Esse artigo parte do pressuposto de que a utilização da Web (2.0) por meio das plataformas interativas juntamente com a mecânica dos jogos (gamificação) podem apresentar resultados satisfatórios para o processo de ensino e aprendizagem. Como resultado, pretende-se apresentar uma proposta da união desses conceitos.

\section{GAMIFICAÇÃO E AMBIENTES ONLINE DE APRENDIZAGEM}

O conceito inicial da gamificação surgiu há muito tempo, visto que a utilização das dinâmicas dos jogos não é contemporânea, pois, desde tempos remotos o homem convive com jogos em distintas épocas, e na maior parte delas, eles estavam influenciando na formação da cultura de civilizações (HUIZINGA, 2012).

Na definição de jogo descrita de Huizinga (2012), o homem passa a ser "Homo Ludens", ou seja, o "homem que brinca", em sua obra o autor faz uma análise sobre o jogo, bem como a 
"noção de jogo e sua expressão na linguagem", para ele autor compreendemos essa definição sobre a ótica como "voluntário".

Para Huizinga (2012, p. 11-14), "[...] o jogo é livre, não é vida corrente, nem vida real, na verdade é uma evasão da vida real; tem característica de faz de conta; processa-se na seriedade; não pertence à vida comum". Na visão desse autor, desde a época de infância o homem brinca, dessa forma é plausível afirmar que o ato de brincar e de jogar se relacionam intimamente e estão conectados com a evolução do pensamento humano.

O termo gamificação é explanado por Vianna et. al. (2013, p. 13): “a gamificação (do original em inglês gamification) corresponde ao uso de mecanismos de jogos orientados ao objetivo de resolver problemas práticos ou de despertar engajamento entre um publico especifico". Assim, a gamificação consiste na utilização de jogos estruturados ou dos elementos presentes nos jogos, que não objetivam o entretenimento, sendo utilizada como método de aprimoramento dos diversos tipos de organizações e instituições, buscando auxiliar o desenvolvimento de processos institucionais.

Em concordância com Vianna et. al. (2013), Alves, Minho e Diniz (2014, p. 74) reforçam a conceptualização da gamificação como a utilização de "mecânicas dos games" em ambientes "non games".

Para Fardo (2013), a gamificação é um fenômeno emergente, proveniente da popularização e popularidade dos games, constituindo assim, um grande passo para a inovação e aproveitamento de oportunidades utilizando-se do fenômeno dos jogos, os quais eram restritos somente a recreação, e que atualmente são muito presentes nas vidas das pessoas.

A dinâmica encontrada nos jogos reflete espontaneamente nas ações vivenciadas fora do mundo dos games, ainda que o jogador não perceba, ele estará vinculando às suas atitudes reais com as atitudes aplicadas nos jogos. Isso ocorre porque muitas vezes as pessoas buscam nos jogos preencher os espaços vazios da sua vida, deixados por terem necessidades não atendidas pelo mundo real (McGONIGAL, 2012).

Torna-se evidente que a gamificação possui um forte apelo psicológico aos seus usuários no que tange a influência indireta das suas ações dos mesmos para alcançar os objetivos do jogo, especialmente porque na atual era da tecnologia, o acesso aos jogos é imensurável, sendo impossível não haver experiências com a sua dinamização, visto que a gamificação está presente no dia-a-dia de diversas pessoas, mesmo que estas não tenham conhecimento sobre isso, transformando simples atividades em processos gamificados, dessa forma, interagindo com a realidade, como ocorre com o aplicativo Fousquare (ABRANTES, 2014; VIANNA et. al., 2013).

Cunha et. al. (2013) afirma que a gamificação pode ser aplicada através da utilização dos elementos de jogos. Pode-se citar como alguns exemplos: objetivos claros, regras, desafios, status (rankings e medalhas), feedback constante, brindes (recompensas e prêmios) etc. Partindo desse pressuposto, torna-se fundamental o entendimento basal de determinados elementos.

Três elementos básicos fundamentais e estratégicos estão interligados, são eles: os objetivos claros, as regras norteadoras e os desafios; Weiller (2012, p. 59-60) assegura que "O objetivo pode ser composto dos mais diferentes desafios", além disso, eles "[...] estão presentes em jogos por meio do sistema de regras que governam a atividade".

Ademais, outro elemento nitidamente presente é o feedback, o qual de acordo com Maximiano (2007), garante a eficácia do retorno da informação para o emissor. Ao aplicar o feedback como elemento presente nos jogos ou em processos gamificados, todas as ações que o indivíduo desempenhar, inclusive as que ele não possua controle, devem receber um feedback instantâneo e efetivo, tornando visíveis os resultados das suas ações (WEILLER, 2012). 
Ainda acerca dos elementos dos jogos, Vianna et. al. $(2013$, p. 36) relata sobre os elementos recompensadores: "O status é o tipo mais explícito de atribuição de recompensas e pode ser encontrado na forma de rankings, [...] distribuição de bagdes e por aferição dos próprios jogadores", enquanto os brindes "traduzem-se como métodos mais simples de recompensa [...], na forma de itens". O quadro 01 expõe as características fundamentais dos elementos dos jogos e como eles são mais espontaneamente percebidos.

\begin{tabular}{|c|c|c|}
\hline ELEMENTO (S) & $\begin{array}{c}\text { CARACTERÍSTICAS } \\
\text { FUNDAMENTAIS }\end{array}$ & PERCEPÇÃo \\
\hline $\begin{array}{c}\text { Objetivos } \\
\text { Regras } \\
\text { Desafios }\end{array}$ & $\begin{array}{c}\text { Estratégia } \\
\text { Planejamento } \\
\text { Embasamento }\end{array}$ & Tutoriais \\
Manuais \\
\hline Feedback & $\begin{array}{c}\text { Comunicação } \\
\text { Visibilidade }\end{array}$ & Respostas \\
\hline $\begin{array}{c}\text { Status } \\
\text { Brindes }\end{array}$ & $\begin{array}{c}\text { Recompensas } \\
\text { Satisfação }\end{array}$ & $\begin{array}{c}\text { Rankings } \\
\text { Medalhas (Bagdes) }\end{array}$ \\
\hline
\end{tabular}

Quadro 01 - Características e percepções sobre os elementos dos jogos.

Relacionando as ideologias dos autores é possível afirmar que alguns elementos dos jogos sempre estiveram presentes no cotidiano do ser humano, influenciando comportamentos e potencializando a aprendizagem, partido disso, a gamificação é uma nova terminologia para algo que já estava presente e não era percebido desta maneira, sendo assim, uma inovação para o desenvolvimento em distintas áreas, como a educação, a comunicação e a empresarial (ALVES; MINHO; DINIZ, 2014).

A lógica presente nos games tem sido usada para área de marketing e processos de formação escolar e profissional. O próprio Ministério da Cultura já reconhece os games como um produto audiovisual, e o Ministério de Educação apoia o desenvolvimento de ambientes gamificados [...] (Alves; Minho; Diniz, 2004, p. 74).

A aplicação da gamificação na educação está em ascensão, sendo cada vez mais aceita e cultivada, inclusive, por órgãos de relevância nacional como o Ministério da Cultura, fato que eleva a efetividade e capacidade do gamificação principalmente em ambientes de aprendizagem, visto que esses ambientes promovem o desenvolvimento de habilidades cognitivas, sociais e motoras (ALVES; MINHO; DINIZ, 2014).

Além disso, assim como Jane McGonigal (2012) afirma que os jogos possuem o poder de mudar o mundo e torná-lo um lugar melhor, é possível afirmar que a gamificação traz consigo um grande potencial de motivação e engajamento em vários ambientes de aprendizagem, especialmente nas instituições de ensino, que possuem a disseminação efetiva de conhecimento para todos os seus discentes como competência organizacional.

Um meio simples e eficiente de aplicação da gamificação no universo educacional é a utilização de "sistemas de rankeamento que promovam a competitividade entre os alunos; e de sistemas de recompensas para trazer mais resultados, elevar a produtividade das aulas e aumentar a quantidade de tempo que os discentes empregam para obtenção de conhecimento fora das instituições de ensino (ALVES; MINHO; DINIZ, 2014).

Se por um lado, a gamificação é capaz de envolver o aluno na resolução de problemas reais ajudando-o a dar significado para aquilo que estuda, de outro, possibilita que o professor elabore estratégias de ensino mais sintonizadas com as demandas dos alunos, apropriando-se da linguagem e estética utilizada nos games para construir espaços de aprendizagem mais prazerosos. 
O processo ensino-aprendizagem é uma via de mão dupla, então se através do gamification, o discente tem aulas mais atrativas, inovadoras e que de alguma maneira marcam positivamente a experiência de aprendizado, ele irá absorver mais conhecimento, consequentemente o docente que está aplicando a gamificação em suas aulas poderá utilizar a experiência nessas aulas e a demanda dos alunos para aprimorar seus métodos de ensino, e utilizar todo o feedback proporcionado pelos discentes para continuar estabelecendo ambientes inovadores e agradáveis (ALVES; MINHO; DINIZ, 2014).

\section{SOCRATIVE COMO PLATAFORMA DE ENSINO-APRENDIZAGEM}

Com a finalidade de ser uma importante ferramenta de coleta de dados e constituição de informação, a plataforma Socrative foi desenvolvida como uma ferramenta aplicável no ambiente online e que pode ser acessada através do computador por meio do endereço http://www.socrative.com/, e também por aplicativo para Smartphone e Tablet ou por meio de um site próprio. Corresponde ao um sistema de resposta do aluno, por meio de Quiz interativos, constituindo assim uma excelente ferramenta que ajuda os professores e alunos a aprender de forma interativa e inovadora por meio de uma interface de simulação. O termo interface é utilizado para denominar as interações em dois ambientes atual e virtual na visão de Lévy (2009).

O ambiente dinâmico, inovador e lúdico, assegurado pelo Socrative (figura 1), é um grande diferencial para o aprimoramento do ensino, visto que poderá trazer benfeitorias para a educação, conectando-a com as tecnologias, esteve presente nos objetivos dos estudiosos responsáveis pela plataforma.

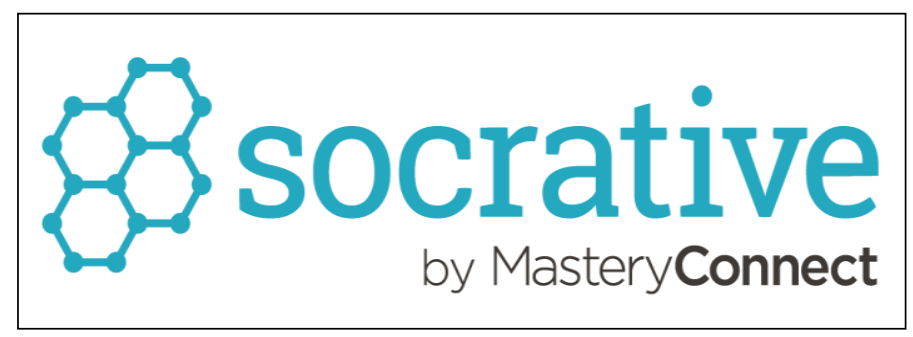

Figura 1 - Logo da plataforma Socrative.

A etapa 01 corresponde à parte de planejamento onde professor pode organizar partir de vários pontos: textos, situação problema, a temática de uma aula. A etapa 02 , momento da interação do professor com a plataforma Socrative, criação dos questionários, e a etapa 03, momento da aula, onde o professor disponibiliza o acesso por meio de código, de forma que os alunos tenham a possibilidade de acessar os quiz e estudar de modo colaborativo (equipes de estudos) e individual, assim, tendo condições para rever o conteúdo, estudar em casa ou no laboratório de informática da instituição de ensino ou de outro local que lhe for conveniente, por sua característica multi-plataforma.

\section{RESULTADOS E DISCUSSÕES}

Não existe como pensar, hoje, em novas práticas educativas sem contar com as ferramentas que a tecnologia da informação e comunicação tem disponibilizado para o desenvolvimento de aulas interativas e com proposta engajadora. $\mathrm{O}$ professor tem o desafio de 
influenciar os alunos nesse novo espaço. Ambos podem ajudar-se mutuamente buscando diversas formas de aprender dentro de um novo espaço do saber, muito mais dinâmico.

Um dos primeiros pontos a ser definido é um objetivo que possa elevar a absorção de informações por parte dos alunos. O desenvolvimento de atividades de ensino que envolve as tecnologias tende a melhorar o desempenho da turma, manter a cooperação e participação de todos os alunos, promover um fluxo contínuo de informações para os professores e alunos, um maior estreitamento no relacionamento docente-discente.

Para o desenvolvimento de uma aula utilizando os conceitos da gamificação e da Web 2.0, faz-se necessário a utilização dos seguintes requisitos:

- Professor capacitado e com propriedade para aplicar efetivamente a metodologia de ensino gamificado;

- Planejamento efetivo da aula;

- Infraestrutura da sala de aula com espaço adequado, conforto e dispondo recursos tecnológicos básicos para a realização da aula;

- Notebook, wi-fi, Datashow;

- Termo de participação dos alunos;

- Apresentação de proposta a turma de como a aula será.

O professor desenvolve os questionários na plataforma (Socrative), a liberação do acosse, podendo ser utilizado por meio de smartphones, tablets ou computadores.

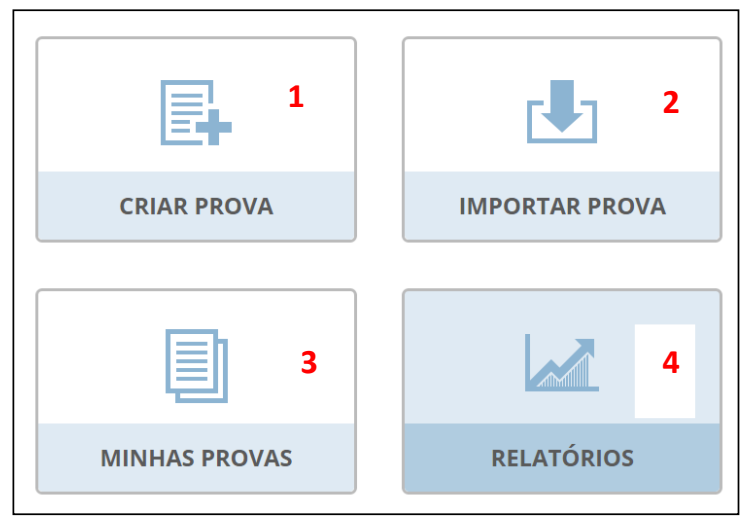

Figura 2 - Interface logado Socrative

\section{Etapas}

1 - Ambiente de criação das provas, podem ser discursivas, de múltipla escolha, certo e errado;

2 - Essas provas podem ser baixadas em formato PDF;

3 - Podem ser visualizadas todas as provas;

4 - Podem ser baixos os resultados conforme realizados pelo professor em equipe ou individual.

O principal benefício das atividades é a sua possibilidade de mensuração do nível de conhecimento de cada aluno e/ou equipe de estudo, bem como, a avaliação do desempenho individual e desempenho da equipe de alunos. Outros, podem também ser destacados como: coleta de dados marcadores para aulas posteriores, ou seja, os itens que os alunos foram ruins, 0 fortalecimento da aprendizagem contínua dos discentes e estímulo à busca de conhecimento. 
Outros que pode se apresentar como forma de engajamento são os sistemas de medalhas que podem ser criados pelo professor. As medalhas são símbolos que representam e materializam as conquistas dos alunos. A proposta das medalhas é gerar competividade natural entre os alunos. As principais regras para conquistar medalhas.

O aluno que coletar a maior quantidade de medalhas será premiado no fim de um período determinado. A figura 3 ilustra e exemplifica as medalhas que podem ser aplicadas da aula gamificada.

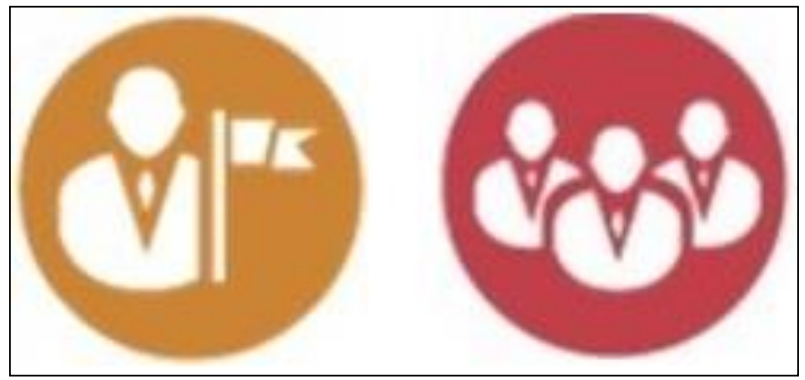

Figura 3 - Exemplo de medalhas

A premiação deve ser palpável e deve instigar os alunos na busca por mais conhecimento. O acompanhamento das medalhas deve ser realizado através de controles em Excel, e deve ser utilizado um sistema de rankeamento dos alunos, assim, torna visível a posição de cada um e quanto cada pessoa deve se esforçar para modificar sua posição.

\section{CONSIDERAÇÕES FINAIS}

Como sugestão das práticas educativas desenvolvidas para utilizar a Web 2.0, ainda está em utilizar essas novas tecnologias apenas como pesquisa, e não como ambientes de informação e comunicação para divulgação de promoção da escola na comunidade em que ela está inserida. As novas práticas pedagógicas devem procurar envolver os alunos juntamente com os professores dando-lhes possibilidades de desenvolver atividades que possam ser produzidas das mais diversas formas: fotos, vídeos, construções de páginas virtuais e compartilhamento. Mais ações devem ser incentivadas: acesso frequente à internet, o uso dos recursos e aplicativos do computador para a construção da página e de outras produções; a socialização das atividades desenvolvidas, a socialização dos conteúdos com os alunos. Claro que esse não é método inovador para a utilização do computador nas escolas, já existe casos bem aceitos, e sucessos individuais, mas seria um bom começo para o desenvolvimento da utilização da Web 2.0 a favor da educação.

Por fim, foi possível analisar os benefícios que a gamificação proporciona às organizações desse estudo, tornando-se claro que a gamificação tornou os métodos de capacitação dos consultores de vendas das organizações partícipes desta pesquisa, mais atraentes e efetivos, visto que, os referidos colaboradores passam a assumir atividades onde eles se tornam indivíduos ativos no processo de aprendizagem, diferentemente do modelo tradicional de multiplicação já utilizado nas organizações, no qual eles são, geralmente, passivos.

Vale salientar que o sucesso da implantação da gamificação em qualquer processo organizacional através da utilização da abordagem dos elementos dos jogos dependerá do emprego da criatividade de quem estiver implantando-a, para que o processo gamificado tornese atrativo e não se transforme em um desperdício de tempo. 


\section{REFERÊNCIAS}

ABRANTES, R. (2014). A jogada: sabedoria dos jogos para jovens visionários. Bestseller. 90 p.

ADOLPHO, C. (2009). Google Marketing: O guia definitivo de Marketing Digital. 2. ed. São Paulo: Novatec.

ALVES, L. R. G.; MINHO, M. R. S.; DINIZ, M. V. C. (2014). Gamificação: diálogos com a educação. In: FADEL, Luciane Maria et al. Gamificação na Educação. São Paulo: Pimenta Cultural, Cap. 3. p. 74-97.

AMORA. D. (2008). Professor, você está preparado para ser dono de um meio de comunicação de massa? (IN). FREIRE, Wendel (org). Tecnologia e educação: as mídias na prática docente. Rio de Janeiro: Wak.

CUNHA, L. F.; GASPARINI, I.; BERKENBROCK, C. D. M. (2014). Investigando o uso de gamificação para aumentar o engajamento em sistemas colaborativos. In: WORKSHOP SOBRE ASPECTOS DA INTERAÇÃO HUMANO-COMPUTADOR NA WEB SOCIAL (WAIHCWS'13), 5, 2013, Manaus. Proceedings. Manaus: Ceur-ws.org, 2013. p. 28 - 33. Disponível em: <http://migre.me/mGWx8>. Acesso em: 03 ago.

FARDO, M. L. (2013). A gamificação aplicada em ambientes de aprendizagem. Revista Renote: Novas Tecnologias da Educação, Caxias do Sul, v. 12, p.1-9, jul. 2013. ISSN 1679-1916 (versão on-line).

HUIZINGA, J. (2000). Homo ludens. 4. ed. São Paulo: Perspectiva, 2000.

LÉVY, P. (1993). As tecnologias da inteligência: o futuro do pensamento na era da informática. Rio de Janeiro: Editora 34.

LÉVY, P. (2009). Cibercultura. (Trad. Carlos Irineu da Costa). São Paulo: Editora 34.

MAXIMIANO, A. C. A. (2007). Introdução à administração. 7. ed. São Paulo: Atlas.

MCGONIGAL, J. (2012). A realidade em jogo: por que os games nos tornam melhores e como ele podem mudar o mundo. Rio de Janeiro: Best Seller Ltda.

SOCRATIVE (2014). Homepage site socrative. Disponível em: <http://www.socrative.com/>. Acesso em: 03 ago.

VIANNA, Y. et. Al (2013). Gamification, Inc. Como reinventar empresas a partir de jogos. Rio de Janeiro: Mjv Press.

WEILLER, T. A. (2012). Game design inteligente: elementos de design de videogames, como funcionam e como utilizá-los dentro e fora de jogos. 2012. 156 f. Dissertação (Mestrado) Curso de Comunicação, Escola de Comunicação e Artes da Universidade de São Paulo, São Paulo. 